\title{
A novel polysaccharide derived from algae extract induces apoptosis and cell cycle arrest in human gastric carcinoma MKN45 cells via ROS/JNK signaling pathway
}

\author{
PEIYU XIE $^{1,2}$, ISAO FUJII ${ }^{1}$, JIEN ZHAO $^{3}$, MAKOTO SHINOHARA ${ }^{3}$ and MAKOTO MATSUKURA ${ }^{1}$ \\ ${ }^{1}$ Laboratory of Clinical Pharmacology and Therapeutics, Faculty of Pharmaceutical Sciences, \\ Sojo University, Kumamoto 860-0822; ${ }^{2}$ Department of Molecular Genetics, \\ Graduate School of Medical Sciences, Kumamoto University, Chuo-ku, Kumamoto 860-8556; \\ ${ }^{3}$ Ashikita Institution for Developmental Disabilities, Ashikita-machi, Kumamoto 869-541, Japan
}

Received June 2, 2016; Accepted August 18, 2016

DOI: 10.3892/ijo.2016.3658

\begin{abstract}
In recent years, interest in biological activities of compounds from marine organisms has intensified. Cancer is the most principal enemy for human life and health. For the first time, to the best of our knowledge, we investigated a novel algae-derived polysaccharide for its role in inducing apoptosis and cell cycle arrest in human gastric carcinoma MKN45 cells. We found that the novel polysaccharide suppressed MKN45 cell proliferation, induced cell apoptosis and arrested the cells at $\mathrm{G} 2 / \mathrm{M}$ phase. Furthermore, we observed that the generation of reactive oxygen species (ROS) and the phosphorylation of Jun N-terminal kinase (JNK), p53, caspase-9 and -3 were induced in the polysaccharide-treated MKN45 cells. In addition, pretreatment with $\mathrm{N}$-acetyl-cysteine (NAC) and SP600125, the inhibitor of ROS and JNK, induced MKN45 cell proliferation, prevented the cell apoptosis and released the cells from cycle arrest. Finally, we found that pretreatment with NAC prevented the JNK, p53, caspase- 9 and -3 protein phosphorylation induced by the polysaccharide, however, pretreatment with SP600125 did not affect the generation of ROS, suggesting that ROS is upstream of JNK. Taken together, the novel polysaccharide induced cancer cell apoptosis and arrested cell cycle via ROS/JNK signaling pathway.
\end{abstract}

\section{Introduction}

Many studies in recent years focused on the activities of compounds extracted from marine organisms (1). Many such compounds have been investigated, and some have been developed into herbal medicine and made commercially available

Correspondence to: Professor Makoto Matsukura, Laboratory of Clinical Pharmacology and Therapeutics, Faculty of Pharmaceutical Sciences, Sojo University, 4-22-1 Ikeda, Kumamoto 860-0822, Japan E-mail:mtmk@ph.sojo-u.ac.jp

Key words: phosphorylation, apoptosis, cell cycle, reactive oxygen species, Jun N-terminal kinase in Japan and even all over the world (2). In the past, we also focused on investigating a novel polysaccharide derived from algae extract for its biological activities (3). The efficiency of the novel algae-extracted polysaccharide was first reported in retinal pigment epithelial (RPE) cells, in which the polysaccharide would protect RPE cells against oxidative damage induced by high-glucose (3). This efficiency of anti-oxidative damage was thought a powerful potential to withdraw the normal cells from some unfavorable circumstance or resist the progress of abnormal cells (cancer cell). However, it is unclear whether this novel polysaccharide could affect cancer cells.

Cancer continue to be the second leading cause of death $(4,5)$. Surgical operation, radiotherapy and chemotherapy are the most common therapies so far, however the side-effects produced by these procedures (especially by chemotherapy) often bring some new problems $(6,7)$.

Due to the limited efficacy of traditional therapy for cancers, we sought to determine a new treatment strategy for cancers. In this study, we for the first time investigated the novel polysaccharide in inducing apoptosis and cell cycle arrest in human gastric carcinoma MKN45 cells.

Apoptosis is an important cause of cell proliferation inhibition (8). There is compelling evidence that excessive reactive oxygen species (ROS) production surmounts cellular antioxidant defenses, triggering apoptosis (9). Apart from apoptosis, cell cycle arrest is another cause of growth inhibition $(10,11)$. Many anticancer agents dampen malignant growth by arresting the cell cycle at the $\mathrm{G} 1, \mathrm{~S}$ or $\mathrm{G} 2 / \mathrm{M}$ phases (12). It is well known that Jun N-terminal kinase (JNK), a member of mitogen-activated protein kinase (MAPK) family, is associated with cell proliferation inhibition $(13,14)$. The activation of JNK is associated with ROS elevation (13). p-JNK activates downstream tumor suppressor p53, caspase-9 and -3 , then leads to apoptosis and cell cycle arrest (15).

In this study, we determined that the novel polysaccharide derived from algae extract induced human cancer cell (MKN45 cell) apoptosis by ROS/JNK signaling pathway and arrested the cell cycle. Our study indicated a novel therapeutic strategy of cancer. 

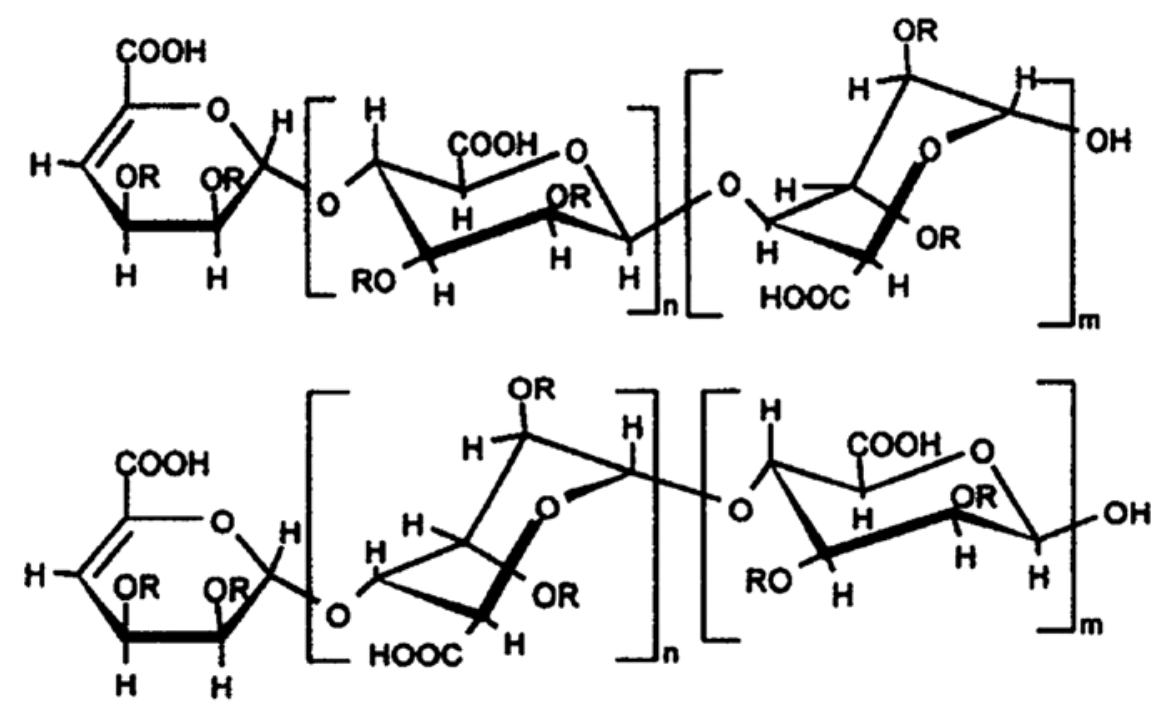

Figure 1. The molecular structure of the novel polysaccharide.

\section{Materials and methods}

Preparation of the novel polysaccharide. The novel polysaccharide (molecular structure was shown as Fig. 1) derived from algae extract was achieved by Toyo Medicine Institute (Ashikita, Kumamoto, Japan). Detailed methods for the preparation of the compound were published elsewhere (16). Briefly, the polysaccharide compound was prepared from a type of phaeophyceae. After being extracted with chloroform, ethyl acetate and n-butyl alcohol, the compound was isolated by column chromatography on silica gel and Sephadex LH-20 columns, was purified on a macroporous absorption resin column, and then sulfonated by sulfuric acid. The structure of the polysaccharide compound is a typical sugar chain structure made of polymeride of disaccharide, which is rich in phenol and sulfate. The average molecular weight of the compound was 11,680. The molecular weight was used for calculation of molar concentration $(\mu \mathrm{M})$.

Cell culture. Human gastric cancer MKN45 cells expressing the Fucci probes (MKN45-Fucci cells) were purchased from RIKEN BioResource Center (Tokyo, Japan). MKN45 cells were cultured in Dulbecco's modified Eagle's medium (DMEM) (Sigma, Tokyo, Japan) supplemented with 10\% FBS. $100 \mathrm{U} / \mathrm{ml}$ penicillin and $100 \mathrm{mg} / \mathrm{ml}$ streptomycin (Sigma), and were cultured in an incubator (Sanyo) with $5 \% \mathrm{CO}_{2}$ at $37^{\circ} \mathrm{C}$.

3-(4,5-Dimethylthiazol-2-yl)-2,5-diphenyltetrazolium bromide (MTT) assay. MKN45 cells were exposed to $100 \mu \mathrm{g} / \mathrm{ml}$ polysaccharide with or without pre-treatment with NAC $(5 \mathrm{mM})$ or SP600125 $(5 \mu \mathrm{M})$. The viability of normal cells and polysaccharide-treated cells was determined by a colorimetric MTT assay according to the method described previously (17). Absorbance at $550 \mathrm{~nm}$ was determined by an MTP-800 microplate reader (Corona Electric, Tokyo, Japan). Absorbance at $690 \mathrm{~nm}$ was also measured to compensate for any interfering effects of cell debris and the microtiter plate. Percentage of viable cell number was calculated as: Optical density (OD) of treated sample/OD of untreated control x 100.
Nuclear staining. MKN45 cells were plated in 6-well plates at the density of $1 \times 10^{5}$ cells/well. After $24-\mathrm{h}$ incubation, the cells were treated with the polysaccharide at a concentration of $100 \mu \mathrm{g} / \mathrm{ml}$ and further incubated for another $48 \mathrm{~h}$. Then the cells were washed with PBS, fixed in $4 \%$ paraformaldehyde (Sigma) for $30 \mathrm{~min}$ and then stained with $20 \mathrm{mg} / \mathrm{ml}$ Hoechst 33342 for $15 \mathrm{~min}$ at room temperature in the dark. Cells were then assessed by fluorescence microscopy for morphological changes.

Fluorescent ubiquitination-based cell cycle indicator (Fucci) system. MKN45 cells were exposed to $100 \mu \mathrm{g} / \mathrm{ml}$ polysaccharide for $48 \mathrm{~h}$. MKN45 cells expressing two Fucci probes: cells emit red fluorescence ( $\mathrm{SCF}^{\mathrm{Skp} 2}$ ) in $\mathrm{G} 1 / \mathrm{G} 0$ phase and green fluorescence ( $\mathrm{APC}^{\mathrm{Cdh} 1}$ ) in $\mathrm{S} / \mathrm{G} 2 / \mathrm{M}$ phases (18). As described (19), fluorescence and phase contrast images were observed using an FV10i-DOC confocal laser scanning microscope (Olympus, Tokyo, Japan) with a UPLSAPO 60x Wobjective lens.

Detection of intracellular ROS. Intracellular accumulation of ROS was estimated using the fluorescent dye $\mathrm{H}_{2}$-DCFDA (Life Technologies, Tokyo, Japan), which is converted to a membrane impermeable and highly fluorescent compound, dichlorofluorescin diacetate (DCF), in the cell in the presence of ROS. The MKN45 cells were seeded in a 6-well plate at the density of $1 \times 10^{5}$ cells/well. Following treatment with the polysaccharide or SP600125 $(5 \mu \mathrm{M})$, MKN45 cells were further incubated for $48 \mathrm{~h}$. The cells were rinsed with a serum-free medium and were incubated in $5 \mu \mathrm{M} \mathrm{H}_{2}$-DCFDA for $60 \mathrm{~min}$ at $37^{\circ} \mathrm{C}$. The cells were then examined under a fluorescence microscope (C1-T-SM; Nikon, Tokyo, Japan), collected and subjected to a fluorescence spectrophotometer (F-2500; Hitachi, Tokyo, Japan) to detect the fluorescence of DCF inside cells (excitation, $488 \mathrm{~nm}$; emission, $521 \mathrm{~nm}$ ) as described (20).

Western blot analysis. Electrophoresis was performed using a vertical slab gel with $12 \%$ polyacrylamide content according to the method described previously (21). The transfer of proteins from the SDS polyacrylamide gel to a membrane was performed 

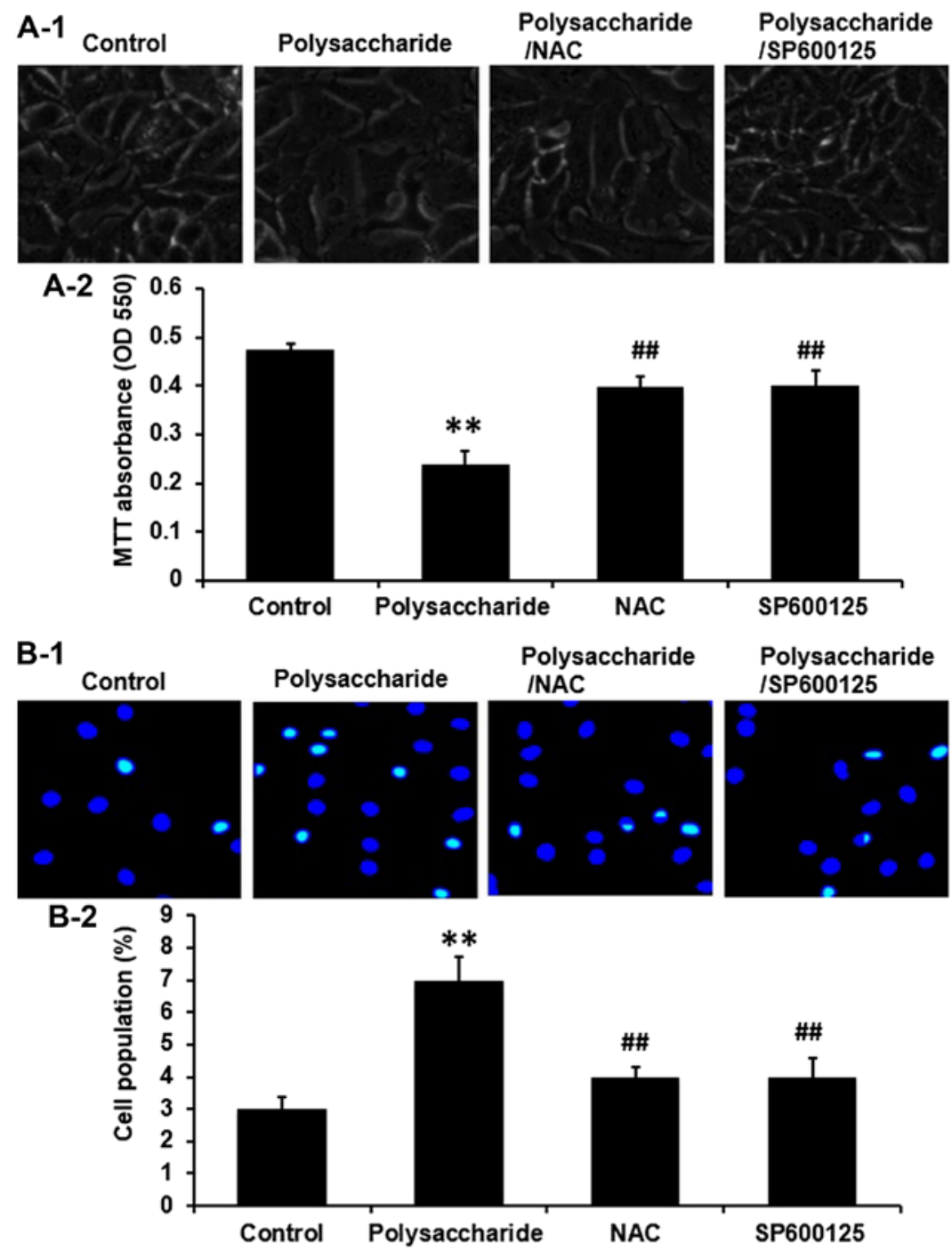

Figure 2. The novel polysaccharide suppressed cell proliferation and induced cell apoptosis in MKN45 cells, NAC and SP600125 inhibited the effects of the novel polysaccharide on cell proliferation and apoptosis. Human gastric cancer MKN45 cells were pretreated with NAC (5 mM) (an inhibitor for ROS) or SP600125 $(5 \mu \mathrm{M})$ (an inhibitor for JNK) for $1 \mathrm{~h}$ prior to the polysaccharide $(100 \mu \mathrm{g} / \mathrm{ml})$ treatment. Then the cells were further incubated for $48 \mathrm{~h}$. (A) The cell viability was determined by MTT assay. (B) The cell apoptosis was determined by nuclear staining. The novel polysaccharide significantly suppressed cell proliferation and induced cell apoptosis. Pretreatment with NAC or SP600125 prevented the polysaccharide-induced cell proliferation and apoptosis in MKN45 cells, significantly. (A-2) The quantification of (A-1). (B-2) The quantification of (B-1). Data are expressed as the mean \pm standard deviation (n=3). $\mathrm{P}<0.05$ was considered to indicate a statistically significant difference $\left({ }^{* *} \mathrm{P}<0.01\right.$, polysaccharide-treated group vs control group; ${ }^{\# /} \mathrm{P}<0.01, \mathrm{NAC}$ or $\mathrm{SP} 600125$ + polysaccharide-treated group vs polysaccharide-treated group).

electrophoretically according to the method described previously (22) with certain modifications using a Semi Dry Electroblotter (Sartorius AG, Goettingen, Germany) for 90 min with an electric current of $15 \mathrm{~V}$. The membrane was treated with Block Ace ${ }^{\mathrm{TM}}(4 \%)$ for $30 \mathrm{~min}$ at $22^{\circ} \mathrm{C}$. The first reaction was performed using rabbit immunoglobulin (IG) $\mathrm{G}$ antibodies against JNK, p-JNK, p53, caspase-9 and -3 (Sigma) in PBS containing $0.03 \%$ Tween- 20 for $1 \mathrm{~h}$ at $22^{\circ} \mathrm{C}$. Following washing in the same buffer, the second reaction was performed using horseradish peroxidase (HRP)-conjugated anti-rabbit goat $\mathrm{IgG}$ $\left(20 \mathrm{ng} / \mathrm{ml}\right.$ ) for $30 \mathrm{~min}$ at $22^{\circ} \mathrm{C}$. After washing, the enhanced chemiluminescence (ECL) reaction was performed on the membrane using the ECL Plus Western Blotting Detection System $^{\mathrm{TM}}$ (GE Healthcare Life Sciences, UK).

Statistical analysis. Analyses were performed using SPSS version 19.0 (IBM SPSS, Armonk, NY, USA). Student's t-test was used and the data are expressed as the mean \pm SD. Each experiment was repeated at least 3 times. $\mathrm{P}<0.05$ was considered to indicate a statistically significant difference.

\section{Results}

The novel polysaccharide suppresses cell proliferation and induces apoptosis in MKN45 cells. Human gastric cancer MKN45 cells were exposed to $100 \mu \mathrm{g} / \mathrm{ml}$ polysaccharide and incubated for $48 \mathrm{~h}$. The cell viability was determined by MTT assay and the cell apoptosis was determined by nuclear staining. The novel polysaccharide significantly suppressed cell proliferation (Fig. 2A), and induced cell apoptosis (Fig. 2B) in MKN45 cells $(\mathrm{P}<0.01)$.

The novel polysaccharide arrests MKN45 cell cycle at G2/M phase. MKN45 cells were exposed to $100 \mu \mathrm{g} / \mathrm{ml}$ polysaccha- 
A
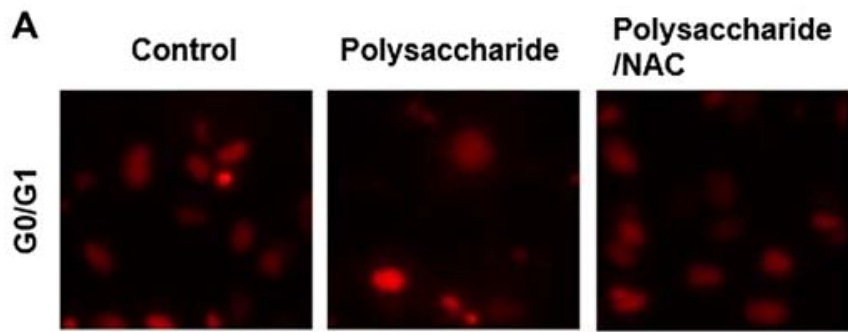

Polysaccharide INAC ISP600125
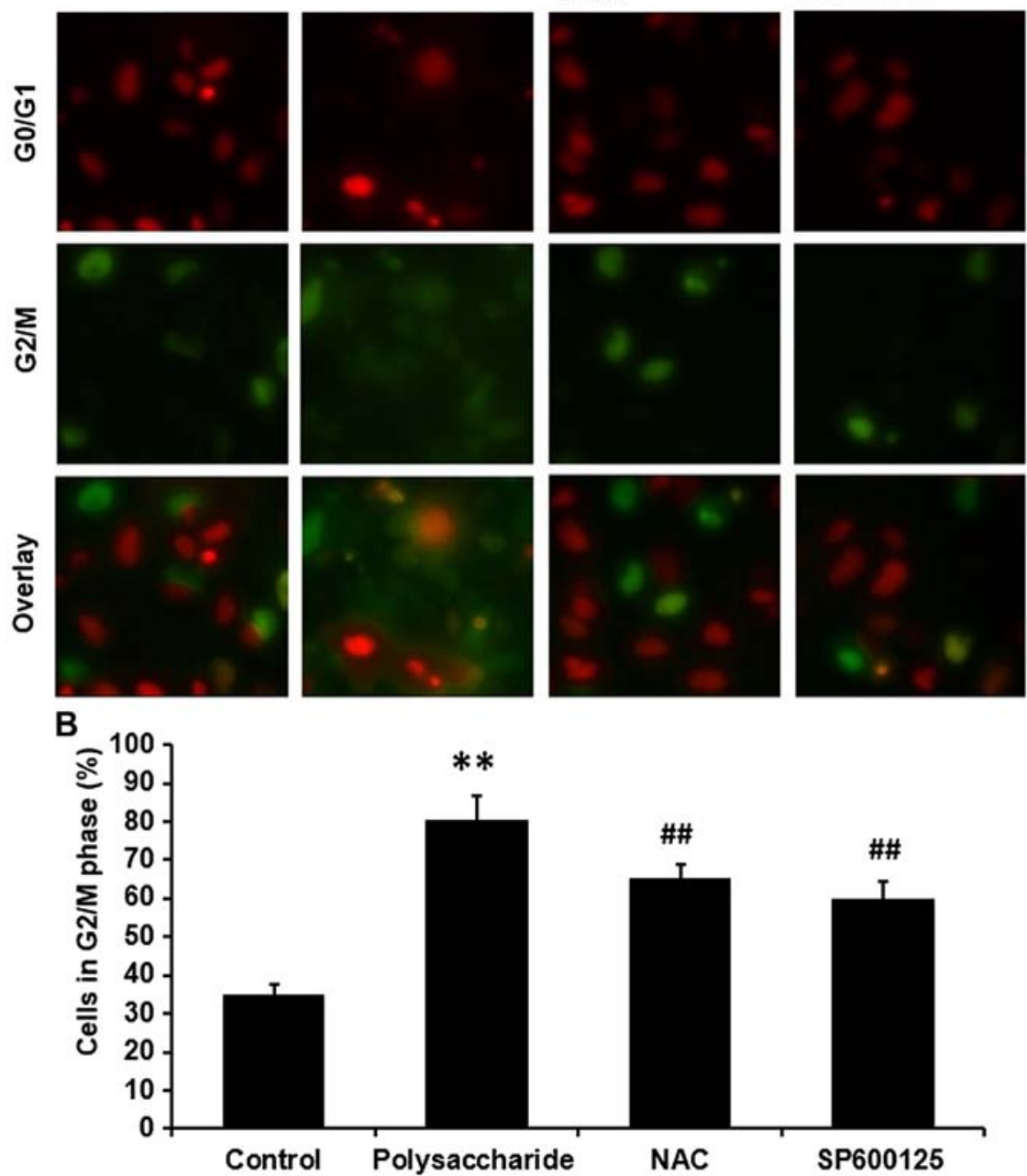

Polysaccharide

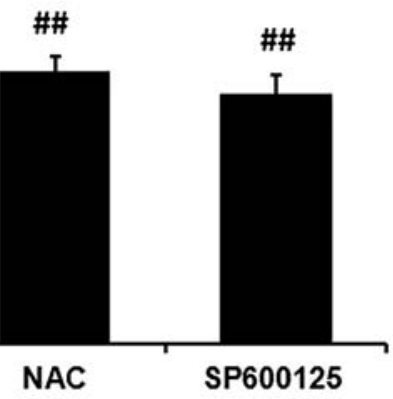

Figure 3. The novel polysaccharide induced cell cycle arrest in MKN45 cells, NAC and SP600125 prevented the polysaccharide-induced cell cycle arrest. MKN45 cells were pretreated with NAC (5 mM) (an inhibitor for ROS) or SP600125 $(5 \mu \mathrm{M})$ (an inhibitor for JNK) for $1 \mathrm{~h}$ prior to the polysaccharide $(100 \mu \mathrm{g} / \mathrm{ml})$ treatment. Then the cells were further incubated for $48 \mathrm{~h}$. The cell cycles were analyzed by the Fucci system. The novel polysaccharide significantly arrested the cell cycle at G2/M phase. Pretreatment with NAC or SP600125 prevented the polysaccharide-induced cell cycle arrest in MKN45 cells significantly. (B) The quantification of (A). Data are expressed as the mean \pm standard deviation $(n=3) . P<0.05$ was considered to indicate a statistically significant difference $\left({ }^{* * *} \mathrm{P}<0.01\right.$, polysaccharide-treated group vs control group; ${ }^{\# \#} \mathrm{P}<0.01, \mathrm{NAC}$ or $\mathrm{SP} 600125$ + polysaccharide-treated group vs polysaccharide-treated group).

ride and incubated for $48 \mathrm{~h}$. The cell cycles were analyzed by Fucci system. The novel polysaccharide significantly arrested the MKN45 cell cycle at $\mathrm{G} 2 / \mathrm{M}$ phase (Fig. 3) $(\mathrm{P}<0.01)$.

The novel polysaccharide induces ROS generation in MKN45 cells. After MKN45 cells were exposed to $100 \mu \mathrm{g} / \mathrm{ml}$ polysaccharide for $48 \mathrm{~h}$, intracellular accumulation of ROS was estimated using the fluorescent dye $\mathrm{H}_{2}$-DCFDA and flow cytometry was estimated using DCFH-DA. The novel polysaccharide significantly induced ROS generation in MKN45 cells (Fig. 4) $(\mathrm{P}<0.01)$.

The novel polysaccharide induces the phosphorylation of $p$-JNK, p53, caspase-9 and -3 in MKN45 cells. MKN45 cells were exposed to $100 \mu \mathrm{g} / \mathrm{ml}$ polysaccharide and incubated for $48 \mathrm{~h}$. The expression levels of p-JNK, p53, caspase- 9 and -3 were determined by western blot analysis. The novel polysaccharide significantly induced the phosphorylation of p-JNK, p53, caspase-9 and -3 in MKN45 cells (Fig. 5) $(\mathrm{P}<0.01)$.
NAC and SP600125 inhibit the effects of the novel polysaccharide on cell proliferation and apoptosis in MKN45 cells. MKN45 cells were pretreated with NAC $(5 \mathrm{mM})$ (the inhibitor for ROS) or SP600125 (5 $\mu \mathrm{M})$ (the inhibitor for JNK) for $1 \mathrm{~h}$ prior to the polysaccharide $(100 \mu \mathrm{g} / \mathrm{ml})$ treatment. Then the cells were further incubated for $48 \mathrm{~h}$. The cell viability and cell apoptosis were determined by MTT assay and nuclear staining, respectively. The novel polysaccharide significantly suppressed MKN45 cell proliferation and induced cell apoptosis. Pretreatment with NAC or SP600125 significantly increased the cell proliferation (Fig. 2A) and prevented cell apoptosis (Fig. 2B) in MKN45 cells ( $\mathrm{P}<0.01)$.

NAC and SP600125 prevent the novel polysaccharide-induced MKN45 cell cycle arrest. MKN45 cells were pretreated with NAC $(5 \mathrm{mM})$ (the inhibitor for ROS) or SP600125 $(5 \mu \mathrm{M})$ (the inhibitor for JNK) for $1 \mathrm{~h}$ prior to the polysaccharide $(100 \mu \mathrm{g} / \mathrm{ml})$ treatment. Then the cells were further incubated for $48 \mathrm{~h}$. The cell cycles were determined by the Fucci system. 
A

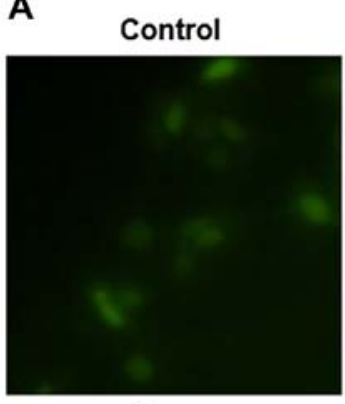

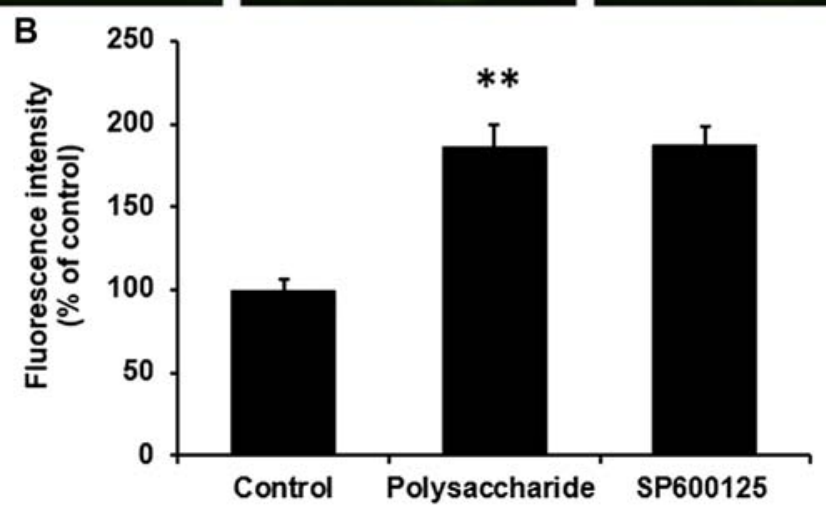

Figure 4. The novel polysaccharide induced the generation of ROS, SP600125 did not affect the novel polysaccharide-induced ROS generation in MKN45 cells. MKN45 cells were pretreated with SP600125 $(5 \mu \mathrm{M})$ (an inhibitor for JNK) for $1 \mathrm{~h}$ before the polysaccharide (100 $\mu \mathrm{g} / \mathrm{ml})$ treatment. Then the cells were

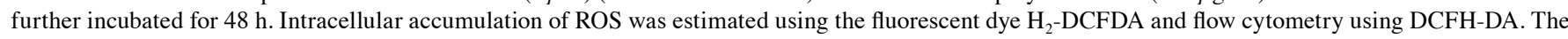
novel polysaccharide significantly induced the ROS generation while SP600125 did not affect the novel polysaccharide-induce ROS generation in MKN45 cells. (B) The quantification of (A). Data are expressed as the mean \pm standard deviation $(n=3)$. $P<0.05$ was considered to indicate a statistically significant

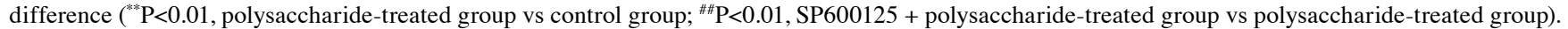
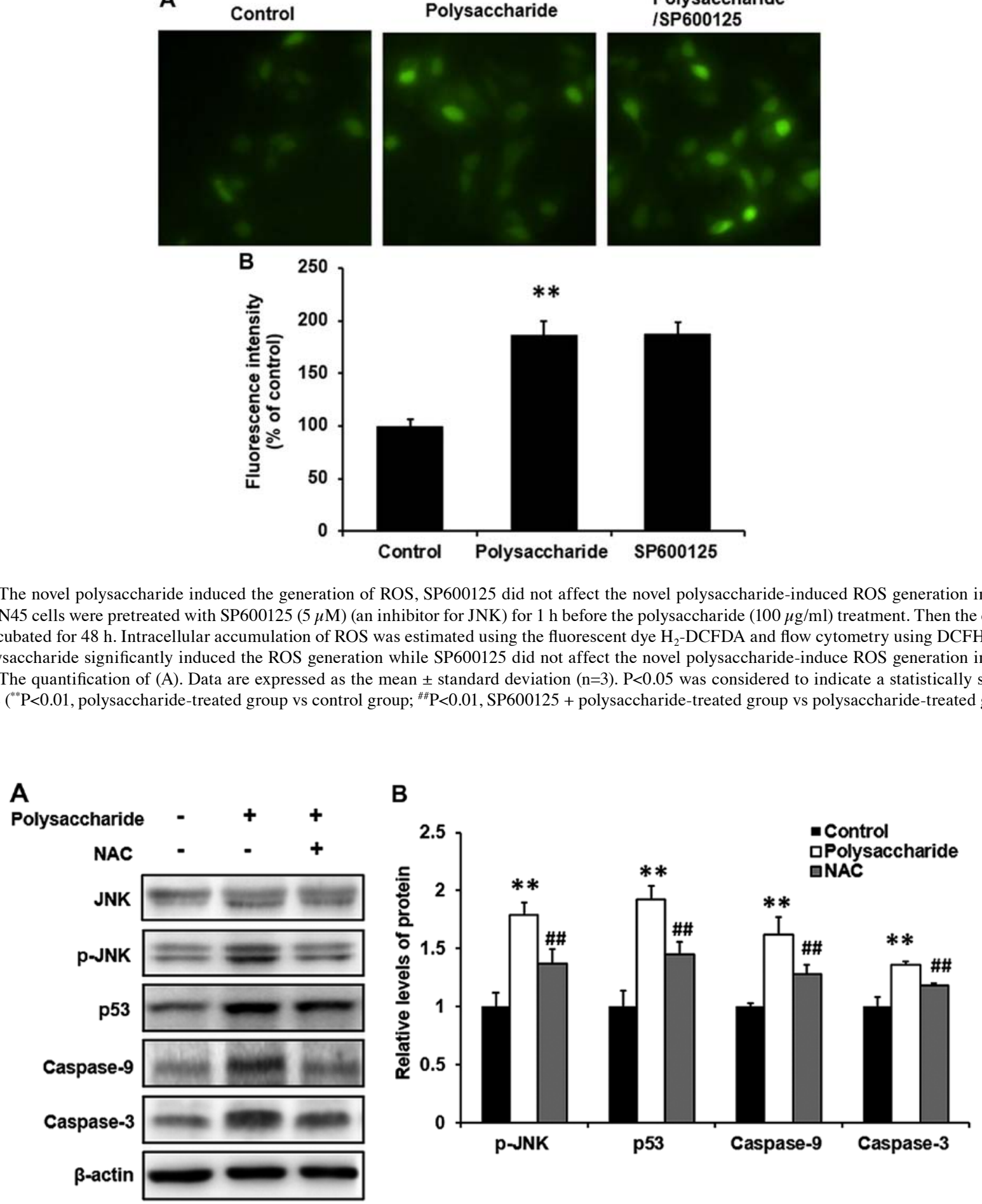

Figure 5. The novel polysaccharide induced phosphorylation of JNK, p53, caspase-9 and -3, NAC prevented the novel polysaccharide-induced protein phosphorylation in MKN45 cells. MKN45 cells were pretreated with NAC (5 mM) (an inhibitor for ROS) for $1 \mathrm{~h}$ before the polysaccharide (100 $\mu \mathrm{g} / \mathrm{ml})$ treatment. Then the cells were further incubated for $48 \mathrm{~h}$. The phosphorylation of JNK, p53, caspase- 9 and -3 were determined by western blot analysis. The novel polysaccharide significantly induced phosphorylation of p-JNK, p53, caspase- 9 and -3 . The novel polysaccharide-induced protein phosphorylation was significantly prevented by the pretreatment with NAC. (B) The quantification of (A). Data are expressed as the mean \pm standard deviation ( $\mathrm{n}=3$ ). $\mathrm{P}<0.05$ was considered to indicate a statistically significant difference ${ }^{\left({ }^{*} \mathrm{P}\right.} \mathrm{P}<0.01$, polysaccharide-treated group vs control group; ${ }^{\sharp \#} \mathrm{P}<0.01, \mathrm{NAC}+$ polysaccharide-treated group vs polysaccharide-treated group).

The novel polysaccharide significantly arrested the MKN45 cell cycle at G2/M phase. Pretreatment with NAC or SP600125 prevented the polysaccharide-induced cell cycle arrest significantly (Fig. 3) $(\mathrm{P}<0.01)$.
NAC prevents the novel polysaccharide-induced phosphorylation of $p$-JNK, p53, caspase- 9 and -3 in MKN45 cells. To further determine the potential signaling pathway involved in the process, MKN45 cells were pretreated with NAC $(5 \mathrm{mM})$ 


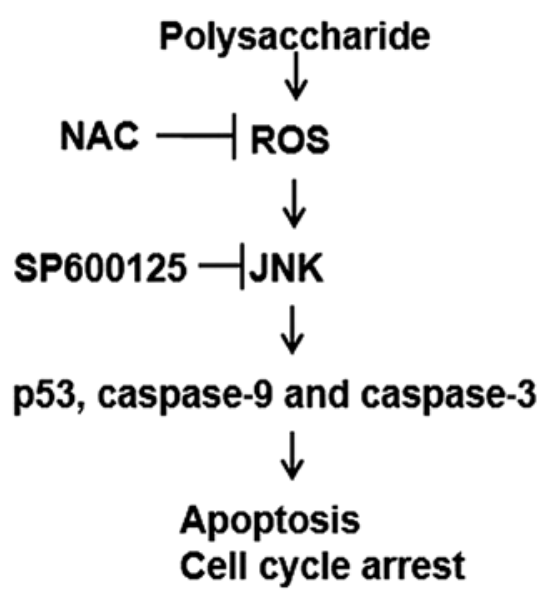

Figure 6. Mechanism of the inhibitory process. The novel polysaccharide derived from algae extract induces the generation of ROS, then enhances the phosphorylation of JNK, and activates the downstream cascades p53, caspase- 9 and -3 , finally suppresses cancer cell proliferation, induces cell apoptosis and arrests the cell cycles.

(an inhibitor for ROS) for $1 \mathrm{~h}$ before the polysaccharide $(100 \mu \mathrm{g} / \mathrm{ml})$ treatment. Then the cells were further incubated for $48 \mathrm{~h}$. The phosphorylation of JNK and p-JNK were determined by western blot analysis. The novel polysaccharide significantly induced the p-JNK phosphorylation, and the novel polysaccharide-induced phosphorylation of p-JNK was significantly prevented by the pretreatment with NAC (Fig. 5) $(\mathrm{P}<0.01)$.

SP600125 does not affect the novel polysaccharide-induce ROS generation in MKN45 cells. MKN45 cells were pretreated with SP600125 (5 $\mu \mathrm{M})$ (an inhibitor for JNK) for $1 \mathrm{~h}$ prior to the polysaccharide $(100 \mu \mathrm{g} / \mathrm{ml})$ treatment. Then the cells were further incubated for $48 \mathrm{~h}$. Intracellular accumulation of ROS was estimated using the fluorescent dye $\mathrm{H}_{2}$-DCFDA and flow cytometry using DCFH-DA. The novel polysaccharide significantly induced ROS generation in MKN45 cells $(\mathrm{P}<0.01)$, however, pretreatment with SP600125 did not affect the polysaccharide-induce ROS generation in MKN45 cells (Fig. 4). These data suggested that ROS is upstream of JNK.

\section{Discussion}

In recent years, as elevating of therapeutic quality of cancer chemotherapy was recognized, researchers focused on the application of marine organisms in molecular treatment for diseases $(1,23)$. Many such marine organism extractedcompounds have been investigated, and some have been developed into herbal medicine and made commercially available in Japan and even all over the world (2). In the past, we focused on investigating a novel polysaccharide derived from algae extract for its biological activities (3) (molecular structure is shown in Fig. 1). In this study, we investigated the activity of the novel polysaccharide on cancer cell apoptosis and cell cycle arrest. The pre-experiments were performed in a dose-dependent manner $(1,10,100$ and $1,000 \mu \mathrm{g} / \mathrm{ml})$ and a time-dependent manner $(12,24$ and $48 \mathrm{~h})$. We found significant difference when the concentration reached $100 \mu \mathrm{g} / \mathrm{ml}$ and the treatment-time reached $48 \mathrm{~h}$, so we decided to use $100 \mu \mathrm{g} / \mathrm{ml}$ of polysaccharide and $48 \mathrm{~h}$ of treatment for our experiments.

Cancer is the principal enemy for human life and health (4), a leading cause of mortality worldwide (24). Chemotherapy and radiotherapy are the most common therapy in the patients when surgical operation is not possible, however the sideeffects are hard to bear and always bring suffering, physically and psychologically $(6,7)$. In consideration of the unwanted side-effects (25), it is crucial to develop new treatment strategies for cancers.

Proliferation and apoptosis are very important physiological processes for cancer cells (26). Apoptosis is an important cause of cell proliferation inhibition (8). Apoptosis (programmed cell death), is an essential mechanism through which many types of chemotherapeutic agents inhibit tumor growth (27). This study demonstrated that the novel polysaccharide suppressed cell proliferation (Fig. 2A) and induced apoptosis (Fig. 2B) in MKN45 cells. Apart from apoptosis, cell cycle arrest is another cause of growth inhibition $(10,11)$. Many anticancer agents dampen malignant growth by arresting the cell cycle at the G1, S or G2/M phases (12). Deregulation of cell cycle has been linked with cancer initiation and progression (28). Arresting the cell cycle is an effective method to regulate cell cycle progression, and contribute to malignant cell proliferation (11). In this study, by using the Fucci system, we confirmed these theories and showed that the novel polysaccharide arrested MKN45 cells at G2/M phase (Fig. 3). These results suggested the potential of the novel polysaccharide as an anti-cancer agent.

ROS, which is the byproduct of normal cellular oxidative processes, has been suggested to regulate the process involved in the initiation of apoptotic signaling (29) and has been implicated in several oncogenic pathways. There is compelling evidence that ROS production surmounts cellular antioxidant defenses, triggering apoptosis (9), and cancer cells are more sensitive to rapid increases in ROS levels than normal cells. ROS-mediated cytotoxicity has also been identified as an important mechanism in some anticancer agents (30). Accumulating evidence indicates that many anticancer agents destroy tumor cells by raising the level of ROS above a toxic threshold (31). Oncogenic transformation elevates basal ROS levels significantly so that any further acute increases can trigger reactivation of the apoptotic program in cancer cells (32). To investigate whether the novel polysaccharide-induced MKN45 cell apoptosis and cell cycle arrest is promoted through an increase in ROS production, we measured ROS levels. Our results showed that the novel polysaccharide induced ROS generation in MKN45 cells significantly (Fig. 4).

It is well known that JNK, a member of mitogen-activated protein kinase (MAPK) family, is associated with cell proliferation inhibition $(13,14)$. Various apoptotic stimuli can rapidly activate MAPKs, which include p-JNK (33). The activation of JNK is associated with ROS elevation (13). p-JNK activates a downstream tumor suppressor (15). p53, caspase-9 and -3 , then leads to apoptosis and cell cycle arrest. p53, a tumor suppressor, is well known for coordinating apoptosis to preserve genomic stability and prevent tumor formation (34). p53 can induce the expression of several factors involved in apoptosis, such as caspase- 9 and -3 (35). The activation of 
caspase- 9 and -3 damage the cell structure and cause functional disorder by proteolysis (36). In addition to cell cycle arrest, p53 also triggers cell cycle arrest to provide time for self-mediated apoptosis through transcriptional activation of cyclin-dependent kinase inhibitor (37). p-JNK activated p53, caspase- 9 and -3 , and finally leads to apoptosis and cell cycle arrest (15). Our study showed that the novel polysaccharide induced the phosphorylation of p-JNK, p53, caspase-9 and -3 (Fig. 5), suggesting the involvement of p-JNK, p53, caspase-9 and -3 in this process.

To better understand the mechanism, we used NAC, an inhibitor for ROS, and SP600125, an inhibitor for JNK. Pretreatment with NAC or SP600125 significantly increased the cell proliferation inhibited by the polysaccharide (Fig. 2A), prevented the polysaccharide-induced cell apoptosis (Fig. 2B) and cell cycle arrest significantly (Fig. 3) in MKN45 cells. Furthermore, we found that pretreatment with NAC prevented the protein phosphorylation induced by the novel polysaccharide (Fig. 5), however, pretreatment with SP600125 did not affect the generation of ROS (Fig. 4), suggesting that the novel polysaccharide induces apoptosis and cell cycle arrest in MKN45 cells via ROS/JNK signaling pathway, and ROS is upstream of JNK.

According to the mechanism described in Fig. 6, the novel polysaccharide derived from algae extract induces the generation of ROS, then enhances the phosphorylation of JNK, and activates the downstream cascades p53, caspase-9 and -3 , finally suppresses cancer cell proliferation, induces cell apoptosis and arrests the cell cycles. The potential of the novel polysaccharide in cancer cells is expected to provide insight into the development of novel clinical treatments for cancers.

\section{References}

1. Wang Y, Nie M, Lu Y, Wang R, Li J, Yang B, Xia M, Zhang H and Li X: Fucoidan exerts protective effects against diabetic nephropathy related to spontaneous diabetes through the $\mathrm{NF}-\kappa \mathrm{B}$ signaling pathway in vivo and in vitro. Int J Mol Med 35 1067-1073, 2015 .

2. Abdjul DB, Yamazaki H, Kanno S, Takahashi O, Kirikoshi R, Ukai K and Namikoshi M: Structures and biological evaluations of agelasines isolated from the Okinawan marine sponge Agelas nakamurai. J Nat Prod 78: 1428-1433, 2015.

3. Xie P, Fujii I, Zhao J, Shinohara M and Matsukura M: A novel polysaccharide compound derived from algae extracts protects retinal pigment epithelial cells from high glucose-induced oxidative damage in vitro. Biol Pharm Bull 35: 1447-1453, 2012.

4. Wu S, Powers S, Zhu W and Hannun YA: Substantial contribution of extrinsic risk factors to cancer development. Nature 529: 43-47, 2016.

5. Xu J, Kochanek KD, Murphy SL and Tejada-Vera B: Deaths: Final data for 2007. Natl Vital Stat Rep 58: 1-19, 2010.

6. Iwamoto T: Clinical application of drug delivery systems in cancer chemotherapy: Review of the efficacy and side effects of approved drugs. Biol Pharm Bull 36: 715-718, 2013.

7. Meirow $D$ and Nugent $D$ : The effects of radiotherapy and chemotherapy on female reproduction. Hum Reprod Update 7: 535-543, 2001.

8. Pal D, Sharma U, Singh SK, Kakkar N and Prasad R: Overexpression of telomere binding factors (TRF1 \& TRF2) in renal cell carcinoma and their inhibition by using SiRNA induce apoptosis, reduce cell proliferation and migration in vitro. PLoS One 10: e0115651, 2015.

9. Myatt SS, Brosens JJ and Lam EW: Sense and sensitivity: FOXO and ROS in cancer development and treatment. Antioxid Redox Signal 14: 675-687, 2011.
10. Tian X, Yang N, Li B, Zhang J, Xu X, Yue R, Li H, Chen L, Shen Y and Zhang W: Inhibition of HL-60 cell growth via cell cycle arrest and apoptosis induction by a cycloartane-labdane heterodimer from Pseudolarix amabilis. Org Biomol Chem 14: 2618-2624, 2016

11. Snoek BC, de Wilt LH, Jansen G and Peters GJ: Role of E3 ubiquitin ligases in lung cancer. World J Clin Oncol 4: 58-69, 2013.

12. Gamet-Payrastre L, Li P, Lumeau S, Cassar G, Dupont MA, Chevolleau S, Gasc N, Tulliez J and Tercé F: Sulforaphane, a naturally occurring isothiocyanate, induces cell cycle arrest and apoptosis in HT29 human colon cancer cells. Cancer Res 60: $1426-1433,2000$

13. Uchakina ON, Ban $\mathrm{H}$ and McKallip RJ: Targeting hyaluronic acid production for the treatment of leukemia: Treatment with 4-methylumbelliferone leads to induction of MAPK-mediated apoptosis in K562 leukemia. Leuk Res 37: 1294-1301, 2013.

14. Deng L, Yang J, Chen H, Ma B, Pan K, Su C, Xu F and Zhang J: Knockdown of TMEM16A suppressed MAPK and inhibited cell proliferation and migration in hepatocellular carcinoma. Onco Targets Ther 9: 325-333, 2016.

15. Leber B, Geng F, Kale J and Andrews DW: Drugs targeting Bcl-2 family members as an emerging strategy in cancer. Expert Rev Mol Med 12: e28, 2010.

16. Zhang D, Fujii I, Lin C, Ito K, Guan H, Zhao J, Shinohara M and Matsukura M: The stimulatory activities of polysaccharide compounds derived from algae extracts on insulin secretion in vitro. Biol Pharm Bull 31: 921-924, 2008.

17. Yuan Z, Feng W, Hong J, Zheng Q, Shuai J and Ge Y: p38MAPK and ERK promote nitric oxide production in cultured human retinal pigmented epithelial cells induced by high concentration glucose. Nitric Oxide 20: 9-15, 2009.

18. Sakaue-Sawano A, Kurokawa H, Morimura T, Hanyu A, Hama H, Osawa H, Kashiwagi S, Fukami K, Miyata T, Miyoshi H, et al: Visualizing spatiotemporal dynamics of multicellular cell-cycle progression. Cell 132: 487-498, 2008.

19. Roccio M, Hahnewald S, Perny M and Senn P: Cell cycle reactivation of cochlear progenitor cells in neonatal FUCCI mice by a GSK3 small molecule inhibitor. Sci Rep 5: 17886, 2015.

20. Rastogi RP, Singh SP, Häder DP and Sinha RP: Detection of reactive oxygen species (ROS) by the oxidant-sensing probe 2',7'-dichlorodihydrofluorescein diacetate in the cyanobacterium Anabaena variabilis PCC 7937. Biochem Biophys Res Commun 397: 603-607, 2010.

21. Laemmli UK: Cleavage of structural proteins during the assembly of the head of bacteriophage T4. Nature 227: 680-685, 1970.

22. Sasaki A, Arawaka S, Sato H and Kato T: Sensitive western blotting for detection of endogenous Ser129-phosphorylated $\alpha$-synuclein in intracellular and extracellular spaces. Sci Rep 5: 14211, 2015.

23. Ho JW, Leung YK and Chan CP: Herbal medicine in the treatment of cancer. Curr Med Chem Anticancer Agents 2: 209-214, 2002

24. Lacroix M1: Abi-Said D, Fourney DR, Gokaslan ZL, Shi W, DeMonte F, Lang FF, McCutcheon IE, Hassenbusch SJ, Holland E, et al: A multivariate analysis of 416 patients with glioblastoma multiforme: Prognosis, extent of resection, and survival. J Neurosurg 95: 190-198, 2001.

25. Messaoudi K, Clavreul A and Lagarce F: Toward an effective strategy in glioblastoma treatment. Part I: Resistance mechanisms and strategies to overcome resistance of glioblastoma to temozolomide. Drug Discov Today 20: 899-905, 2015.

26. Peng R, Li Z, Lin Z, Wang Y, Wang W, Hu B, Wang X, Zhang J, Wang Y, Zhou R, et al: The HSP90 inhibitor 17-PAG effectively inhibits the proliferation and migration of androgen-independent prostate cancer cells. Am J Cancer Res 5: 3198-3209, 2015.

27. Cooper WA, Kohonen-Corish MR, Zhuang L, McCaughan B, Kennedy C, Screaton G, Sutherland RL and Lee CS: Role and prognostic significance of tumor necrosis factor-related apoptosis-inducing ligand death receptor DR5 in nonsmall-cell lung cancer and precursor lesions. Cancer 113: 135-142, 2008.

28. Drexler HG: Review of alterations of the cyclin-dependent kinase inhibitor INK4 family genes p15, p16, p18 and p19 in human leukemia-lymphoma cells. Leukemia 12: 845-859, 1998.

29. Dewaele M, Maes H and Agostinis P: ROS-mediated mechanisms of autophagy stimulation and their relevance in cancer therapy. Autophagy 6: 838-854, 2010. 
30. Kirshner JR, He S, Balasubramanyam V, Kepros J, Yang CY, Zhang M, Du Z, Barsoum J and Bertin J: Elesclomol induces cancer cell apoptosis through oxidative stress. Mol Cancer Ther 7: 2319-2327, 2008

31. You BR and Park WH: Zebularine-induced apoptosis in Calu-6 lung cancer cells is influenced by ROS and GSH level changes. Tumour Biol 34: 1145-1153, 2013.

32. Trachootham D, Alexandre J and Huang P: Targeting cancer cells by ROS-mediated mechanisms: A radical therapeutic approach? Nat Rev Drug Discov 8: 579-591, 2009.

33. Kong D, Zheng T, Zhang M, Wang D, Du S, Li X, Fang J and Cao X: Static mechanical stress induces apoptosis in rat endplate chondrocytes through MAPK and mitochondria-dependent caspase activation signaling pathways. PLoS One 8: e69403, 2013.
34. An HK, Kim KS, Lee JW, Park MH, Moon HI, Park SJ, Baik JS, $\mathrm{Kim} \mathrm{CH}$ and Lee YC: Mimulone-induced autophagy through p53-mediated AMPK/mTOR pathway increases caspase-mediated apoptotic cell death in A549 human lung cancer cells. PLoS One 9: e114607, 2014.

35. Wang Q, Su L, Liu N, Zhang L, Xu W and Fang H: Cyclin dependent kinase 1 inhibitors: A review of recent progress. Curr Med Chem 18: 2025-2043, 2011.

36. Lee K, Hart MR, Briehl MM, Mazar AP and Tome ME: The copper chelator ATN-224 induces caspase-independent cell death in diffuse large B cell lymphoma. Int J Oncol 45: 439-447, 2014.

37. Lane DP: Cancer. p53, guardian of the genome. Nature 358: 15-16, 1992. 